\title{
New Insights into Interspecific Hybridization in Lemna L. Sect. Lemna (Lemnaceae Martinov)
}

\author{
Luca Braglia (D), Diego Breviario D , Silvia Giani, Floriana Gavazzi, Jacopo De Gregori and Laura Morello *(D)
}

check for

updates

Citation: Braglia, L.; Breviario, D.; Gianì, S.; Gavazzi, F.; De Gregori, J.; Morello, L. New Insights into Interspecific Hybridization in Lemna L. Sect. Lemna (Lemnaceae Martinov). Plants 2021, 10, 2767. https:// doi.org/10.3390/plants10122767

Academic Editors: Viktor Oláh,

Klaus-Jürgen Appenroth and

K. Sowjanya Sree

Received: 15 November 2021

Accepted: 9 December 2021

Published: 15 December 2021

Publisher's Note: MDPI stays neutral with regard to jurisdictional claims in published maps and institutional affiliations.

Copyright: (c) 2021 by the authors. Licensee MDPI, Basel, Switzerland. This article is an open access article distributed under the terms and conditions of the Creative Commons Attribution (CC BY) license (https:/ / creativecommons.org/licenses/by/ $4.0 /)$.
Istituto Biologia e Biotecnologia Agraria, Via Alfonso Corti 12, 20131 Milano, Italy; braglia@ibba.cnr.it (L.B.); breviario@ibba.cnr.it (D.B.); giani@ibba.cnr.it (S.G.); gavazzi@ibba.cnr.it (F.G.); degregori@ibba.cnr.it (J.D.G.)

* Correspondence: morello@ibba.cnr.it; Tel.: +39-02-2369-9686

Abstract: Duckweeds have been increasingly studied in recent years, both as model plants and in view of their potential applications as a new crop in a circular bioeconomy perspective. In order to select species and clones with the desired attributes, the correct identification of the species is fundamental. Molecular methods have recently provided a more solid base for taxonomy and yielded a consensus phylogenetic tree, although some points remain to be elucidated. The duckweed genus Lemna L. comprises twelve species, grouped in four sections, which include very similar sister species. The least taxonomically resolved is sect. Lemna, presenting difficulties in species delimitation using morphological and even barcoding molecular markers. Ambiguous species boundaries between Lemna minor L. and Lemna japonica Landolt have been clarified by Tubulin Based Polymorphism (TBP), with the discovery of interspecific hybrids. In the present work, we extended TBP profiling to a larger number of clones in sect. Lemna, previously classified using only morphological features, in order to test that classification, and to investigate the possible existence of other hybrids in this section. The analysis revealed several misidentifications of clones, in particular among the species L. minor, L. japonica and Lemna gibba L., and identified six putative 'L. gibba' clones as interspecific hybrids between L. minor and L. gibba.

Keywords: duckweeds; Lemnaceae; interspecific hybrids; tubulin-based polymorphism; $\beta$-tubulin

\section{Introduction}

The genus Lemna L. (Lemnaceae, Martinov) [1] is thought to have originated around 41.7 MYA (crown age) from a common ancestor which separated from the Wolffioideae Engl. (genera Wolffia Horkel ex Schleiden and Wolffiella Hegelm.) branch around 54.4 MYA [2]. Its most probable origin has been established as around 16.4-41.7 MYA in North America. According to the latest taxonomic revision, uniting Lemna minuta Kuntz with Lemna valdiviana Phil., the genus Lemna comprises 12 species [3], grouped in four monophyletic sections: Alatae Hegelm., Uninerves Hegelm., Biformes Landolt, and Lemna [4]: this categorisation into sections is also supported by GBS data [5]. Sect. Lemna includes seven species, among which we can find the most cosmopolitan Lemna gibba L. and Lemna minor L., as well as geographically restricted species such as Lemna disperma Hegelm. (Oceania) and Lemna obscura (Austin) Daubs (South-East coast of North America and Ecuador). This is the most problematic section within the taxonomically complex genus Lemna, in which boundaries between some species seem to blur, due to extremely similar morphology. Species can be distinguished from each other based on few, recently updated, key features [3], some of which refer to flowers or fruits, rarely observed in many species. Although sufficient in most cases, key features may vary within the same species among clones or under different growth conditions, particularly upon in vitro cultivation, making identification difficult.

For example, L. gibba is usually easily recognized for the inflated (gibbous) form of the frond caused by enlarged air spaces in the aerenchyma tissue. However, morphological variability in L. minor and L. gibba has long been known, and discrimination between the two becomes particularly difficult when air spaces of L. gibba are reduced, making 
fronds flat [6-8]. This has led to grouping the two species in the L. minor-L. gibba group, or complex, which identifies a continuum between the two [8,9]. Both species are long-day plants which sometimes share the same habitat. Variations in frond morphology in L. gibba may be seasonal. but the occurrence of mixed populations of gibbous and permanently 'flat forms' of $L$. gibba (L. minor-like) has been repeatedly reported in The Netherlands, together with supposed transition forms between the two species, which could not be assigned with certainty to either of the two $[9,10]$.

Species with intermediate traits between L. minor and L. gibba, but bearing some distinctive features have been described in the past, such as Lemna parodiana Giardelli in Argentina [11] and Lemna symmeter Giuga, in Southern Italy [12]. In the absence of further evidence, such species have been considered conspecific with L. gibba [13].

Intraspecific variability in L. minor is represented by reported differences in chromosome numbers, from 40 to 50, and by different genome size reported among clones [14,15], although data are not always consistent because of the small chromosome size and variability in genome size estimation by different methods of measurements. It is therefore difficult to say how much the wide morphological intraspecific diversity observed could be due to phenotypic plasticity or to genetic diversity.

Lemna disperma shows a combination of characters of L. gibba and L. minor [16], but it is restricted to Australia and New Zealand. Similarly, L. obscura, was previously identified either as L. minor or L. gibba but is limited to temperate regions of North America [16]. In both cases, morphological classification is often supported by geographical distribution. A further species in this section, former Lemna ecuadoriensis Landolt, is now considered conspecific with L. obscura [17].

Moreover, Lemna turionifera Landolt, of Northern Asia and America, can be occasionally confused with L. minor and L. gibba by frond morphology, but fruits and seed characters, together with turion-forming ability, provide distinctive traits. Lemna japonica was described as a new species in 1980 as a biotype of L. minor with a limited geographical distribution and posited as a possible interspecific hybrid between L. minor and L. turionifera [18]. This hypothesis was supported by intermediate allozyme pattern shown by L. japonica clones with respect to other similar specimens collected in Japan and likely corresponding to L. minor and L. turionifera respectively [19]. This evidence was recently supported by genetic proofs based on intron length polymorphism in the $\beta$-tubulin genes (also known as Tubulin Based Polymorphism, TBP) and AFLP. Accordingly, L. japonica is hereafter indicated as Lemna $\times$ japonica to indicate the hybrid status of this taxon, assessed as L. minor-SubCluster II (L. minor sensu lato) in our previous work [20]. Its similarity with L. minor is therefore evident and is the cause of frequent misclassifications.

The species most recently included in the section is Lemna trisulca, formerly separated in the single-species sect. Hydrophylla Dumort. This species has a unique morphology with submerged, narrowly ovate fronds connected to a green stalk, often forming branched chains. Despite this peculiarity, the combined data cladogram (morphological, flavonoid, allozyme and DNA sequence data) first obtained by Les [4] clearly placed L. trisulca within sect. Lemna, as later confirmed by nuclear and plastid molecular markers [21]. In some cases, even the more distantly related species like L. minuta, native to America but invasive in Europe [22], can be distinguished from the European native L. minor only by quantitative morphometry [23]. The advent of molecular taxonomy has greatly facilitated species delimitation among duckweeds by AFLP fingerprinting $[24,25]$ and plastid barcoding sequences as $p s b K-p s b I$ and atpF-atpH, which are now commonly used for accurate identification of clones [26,27]. Nuclear and plastid molecular markers have also bolstered phenetics in improving phylogenetic studies $[4,21]$ on duckweeds. However, despite this progress, phylogenetic uncertainty still persists among some lineages and some nodes resolved incongruently by using plastid and nuclear ribosomal sequences [21]. This has been repeatedly attributed to potential interbreeding or incomplete divergence, although neither has ever been demonstrated. The application of high-throughput methods as genotyping-by-sequencing (GBS) has helped to resolve those problematic species bound- 
aries in the genus where plastid sequences alone were inadequate as in the case of L. minor and L. Xjaponica [5]. This observation is in accordance with the maternal inheritance of plastids from L. minor, in the light of the finding that L. × japonica is of hybrid origin [20]. On the one hand, some interpretive problems may have arisen because some accessions were not identified accurately [4] while, on the other, when many clones of the same species were compared, molecular marker analysis enabled uncovering possible misclassifications of clones $[20,24,26]$, particularly in sect. Lemna.

To this end, TBP fingerprinting has been particularly suitable for species delimitation in the genus [20]. This genetic profiling method had been successfully applied to species and subspecies level discrimination in different plant families [28-30]. The Landolt Duckweed Collection (LDC, Rotterdam, The Netherlands, http:/ / www.duckweed.ch (accessed on 8 June 2021)) is perhaps the most important historical collection worldwide, with over 500 clones left of the more than 1000 collected and morphologically classified over 70 years by Professor Elias Landolt in Zürich, $\mathrm{CH}$. Many replicated clones are also present in the collections of the Rutgers Duckweed Stock Cooperative (http: / / www.ruduckweed.org / (accessed on 14 December 2021)) and at the University of Jena and are being investigated in many laboratories worldwide. Although many clones have been investigated by molecular markers, a large part of the collection remains genetically unexplored. As TBP profiling provides a simple way for duckweed species discrimination without sequencing, we planned to investigate all LDC's clones, under an agreement with Mr. W. Lämmler, the manager of the LDC.

We started with a large selection of clones, about 100 in the problematic Lemna sect. Lemna, with the dual aim of verifying the morphological classification of each clone and of finding evidence for the existence of other interspecific hybrids in this section. Given the importance of the LDC as a fundamental resource for scientists working in the field, our data provide useful information for further investigations and for a critical revision of the literature. Interspecific relationships within sect. Lemna are also investigated by length and sequence similarity in $\beta$-tubulin introns. Moreover, leveraging the high genetic variability of such regions, introns are also used as a suitable source of SNPs for the evaluation of intraspecific variability.

\section{Results}

\subsection{TBP Profiling of Duckweed Clones in Lemna Sect. Lemna}

TBP was demonstrated to be a reliable tool for clustering Lemna clones according to the respective species, as validated by plastid markers [20]. Distinctive amplification profiles are obtained for each species, with some intraspecific allelic variations. Ninetyeight duckweed clones belonging to sect. Lemna were analyzed by TBP profiling of the first and second $\beta$-tubulin introns (Table 1 and Supplementary Table S1). Fifty-seven clones belonging to the same section and analyzed in the previously mentioned work [20] were added to the cluster analysis, with Landoltia punctata clone 9354 used as an outgroup. The scoring of the Capillary Electrophoresis TBP (CE-TBP) peaks revealed 139 polymorphic markers across the seven Lemna species (87 and 52 from the 1st and the 2 nd intron region, respectively). The derived dendrogram is shown in Figure 1.

The separation of the seven Lemna species forming the section, according to their genetic similarity by TBP, allowed the unequivocal reclassification of those clones which do not correspond to their morphological description. The hybrid status of L. ×japonica is confirmed here by this larger dataset. In fact, all the clones in this cluster, which includes the L. × japonica holotype 7182, showed hybrid TBP profiles between L. minor and L. turionifera, reflecting the duplicate set of six $\beta$-tubulin genes, whereas all clones in the L. minor cluster have similar pattern among each other, with just six main peaks. Despite the low bootstrap values $(<50 \%)$ of this branch, the tree topology is clearly due to the fact that $L$. $\times$ japonica shares alleles with both putative parental species L. minor and L. turionifera. Interestingly, through the whole tree, high probability support was given to some sub-clusters indicating intraspecific allelic variance among populations (in Figure 1). Separation was in agreement 
with the geographical origin of clones, as in the case of the American clusters of L. $\times$ japonica, L. turionifera (the only American clone) and L. gibba, the East Asian clusters of L. $\times$ japonica and L. turionifera and a Mediterranean group of L. gibba (Figure 1).

Table 1. List of the plant material and reclassification of clones by TBP analysis.

\begin{tabular}{|c|c|c|c|c|c|}
\hline \multirow{2}{*}{ Clone ID } & \multirow{2}{*}{ Collection } & \multirow{2}{*}{ Continent/Region } & \multirow{2}{*}{ Country } & \multicolumn{2}{|c|}{ Classification System } \\
\hline & & & & Morphological Characters & TBP Analysis \\
\hline 0050 & Landolt Collection & Asia & China & L. japonica & L. $\times$ japonica \\
\hline 0078 & Landolt Collection & Asia & China & L. japonica & L. × japonica \\
\hline 0150 & Landolt Collection & Asia & China & L. japonica & L. $\times$ japonica \\
\hline 0190 & Landolt Collection & North America & USA & L. japonica & L. gibba* \\
\hline 0198 & Landolt Collection & Asia & China & L. japonica & L. × japonica \\
\hline 6580 & Landolt Collection & North America & USA & L. minor & L. × japonica* \\
\hline 6591 & Landolt Collection & North America & USA & L. minor & L. minor \\
\hline 6619 & Jena University & North America & USA & L. turionifera & L. turionifera \\
\hline 6728 & Jena University & North America & USA & L. turionifera & L. × japonica* \\
\hline 6742 & Landolt Collection & North America & USA & L. japonica & L. ×japonica \\
\hline 6745 & Landolt Collection & North America & USA & L. gibba & L. gibba \\
\hline 6853 & Jena University & North America & Canada & L. turionifera & L. turionifera \\
\hline 6861 & Landolt Collection & Europe & Italy & L. gibba & L. gibba $\times$ L. Minor * \\
\hline 7018 & Landolt Collection & Asia & Turkey & L. minor & L. minor \\
\hline 7021 & Landolt Collection & Europe & Spain & L. gibba & L. × japonica* \\
\hline 7123 & Landolt Collection & North America & Canada & L. minor & L. × japonica* \\
\hline 7182 & Landolt Collection & East Asia & Japan & L. japonica & L. ×japonica \\
\hline 7295 & Landolt Collection & Africa & Libya & L. minor & L. minor \\
\hline 7320 & Landolt Collection & Africa & Egypt & L. gibba & L. gibba $\times$ L. Minor * \\
\hline 7427 & Landolt Collection & East Asia & Japan & L. turionifera & L. turionifera \\
\hline 7432 & Landolt Collection & East Asia & Japan & L. japonica & L. turionifera * \\
\hline 7537 & Landolt Collection & Europe & Spain & L. gibba & L. × japonica* \\
\hline 7641 & Landolt Collection & Asia & Israel & L. gibba & L. gibba $\times$ L. Minor * \\
\hline 7683 & Landolt Collection & Asia & South Korea & L. turionifera & L. turionifera \\
\hline 7705 & Landolt Collection & India & India & L. gibba & L. gibba \\
\hline 7767 & Landolt Collection & Oceania & Australia & L. disperma & L. disperma \\
\hline 7777 & Landolt Collection & Oceania & Australia & L. disperma & L. disperma \\
\hline 7798 & Landolt Collection & South America & Peru & L. gibba & L. gibba \\
\hline 7816 & Landolt Collection & Oceania & Australia & L. disperma & L. disperma \\
\hline 7856 & Landolt Collection & North America & USA & L. obscura & L. obscura \\
\hline 7868 & Jena University & Europe & Ireland & L. japonica & L. × japonica \\
\hline 7922 & Landolt Collection & South America & Argentina & L. gibba & L. gibba \\
\hline 7951 & Landolt Collection & Asia & China & L. turionifera & L. turionifera \\
\hline 8227 & Landolt Collection & North America & USA & L. obscura & L. obscura \\
\hline 8428 & Landolt Collection & Europe & Switzerland & L. gibba & L. gibba \\
\hline 8434 & Landolt Collection & North America & Canada & L. minor & L. × japonica* \\
\hline 8653 & Landolt Collection & Asia & China & L. japonica & L. ×japonica \\
\hline 8697 & Landolt Collection & East Asia & Japan & L. japonica & L. × japonica \\
\hline 8717 & Landolt Collection & Oceania & Australia & L. L. disperma & L. disperma \\
\hline 8760 & Landolt Collection & Europe & Czech Republic & L. turionifera & L. turionifera \\
\hline 8892 & Landolt Collection & North America & USA & L. obscura & L. obscura \\
\hline 9016 & Landolt Collection & East Asia & Japan & L. japonica & L. × japonica \\
\hline 9109 & Jena University & Europe & Poland & L. turionifera & L. turionifera \\
\hline 9223 & Landolt Collection & Europe & United Kingdom & L. minor & L. minor \\
\hline 9240 & Landolt Collection & Europe, Asia & Russia & L. minor & L. minor \\
\hline 9248 & Landolt Collection & Europe & Italy & L. gibba & L. gibba $\times$ L. Minor * \\
\hline 9250 & Landolt Collection & Europe & Finland & L. japonica & L. Xjaponica \\
\hline 9253 & Landolt Collection & Europe & Finland & L. minor & L. minor \\
\hline 9254 & Landolt Collection & Europe & Finland & L. turionifera & L. turionifera \\
\hline 9285 & Landolt Collection & Asia & China & L. japonica & L. $\times$ japonica \\
\hline 9330 & Landolt Collection & Asia & China & L. japonica & L. $\times$ japonica \\
\hline
\end{tabular}


Table 1. Cont.

\begin{tabular}{|c|c|c|c|c|c|}
\hline \multirow{2}{*}{ Clone ID } & \multirow{2}{*}{ Collection } & \multirow{2}{*}{ Continent/Region } & \multirow{2}{*}{ Country } & \multicolumn{2}{|c|}{ Classification System } \\
\hline & & & & Morphological Characters & TBP Analysis \\
\hline 9345 & Landolt Collection & Europe & Switzerland & L. minor & L. minor \\
\hline 9352 & Landolt Collection & Europe & Albania & L. gibba & L. gibba \\
\hline 9421 & Landolt Collection & North America & USA & L. japonica & L. × japonica \\
\hline 9424 & Landolt Collection & Europe & Germany & L. minor & L. minor \\
\hline 9429 & Jena University & Europe, Asia & Russia & L. turionifera & L. $\times$ japonica* \\
\hline 9435 & Landolt Collection & Europe & Albania & L. gibba & L. gibba \\
\hline 9438 & Landolt Collection & Europe & Czech Republic & L. minor & L. minor \\
\hline 9439 & Landolt Collection & Europe & Germany & L. minor & L. $\times$ japonica* \\
\hline 9470 & Landolt Collection & Europe & United Kingdom & L. turionifera & L. turionifera \\
\hline 9471 & Jena University & Europe & United Kingdom & L. turionifera & L. turionifera \\
\hline 9478 & Jena University & Europe & Poland & L. turionifera & L. turionifera \\
\hline 9480 & Landolt Collection & Europe, Asia & Russia & L. turionifera & L. turionifera \\
\hline 9482 & Landolt Collection & Europe & Italy & L. minor & L. minor \\
\hline 9483 & Landolt Collection & Europe & Albania & L. minor & L. $\times$ japonica* \\
\hline 9485 & Landolt Collection & Europe & Ireland & L. minor & L. minor \\
\hline 9532 & Landolt Collection & Europe & Macedonia & L. minor & L. ×japonica* \\
\hline 9534 & Landolt Collection & Europe & Germany & L. minor & L. minor \\
\hline 9542 & Landolt Collection & Europe & Italy & L. minor & L. $\times$ japonica * \\
\hline 9561 & Landolt Collection & Europe & Sweden & L. minor & L. minor \\
\hline 9562 & Jena University & Europe & Germany & L. gibba & L. gibba $\times$ L. Minor * \\
\hline 9574 & Landolt Collection & Oceania & New Zealand & L. minor & L. minor \\
\hline 9577 & Landolt Collection & Europe & Italy & L. gibba & L. gibba \\
\hline 9591 & Landolt Collection & Europe & Hungary & L. gibba & L. × japonica* \\
\hline 9598 & Landolt Collection & Europe & Germany & L. gibba & L. gibba \\
\hline 9660 & Landolt Collection & Asia & China & L. japonica & L. $\times$ japonica \\
\hline 9942 & Landolt Collection & Europe & Norway & L. minor & L. minor \\
\hline 9951 & Landolt Collection & Europe & France & L. gibba & L. $\times$ japonica* \\
\hline 9952 & Landolt Collection & Europe & France & L. minor & L. minor \\
\hline 9961 & Landolt Collection & Europe & Germany & L. minor & L. minor \\
\hline 9965 & Landolt Collection & Europe & Switzerland & L. gibba & L. × japonica* \\
\hline 9967 & Landolt Collection & Europe & Switzerland & L. minor & L. minor \\
\hline 9969 & Landolt Collection & Europe & Switzerland & L. minor & L. $\times$ japonica* \\
\hline 9973 & Landolt Collection & Europe & Germany & L. minor & L. minor \\
\hline 9977 & Landolt Collection & Europe & Germany & L. minor & L. minor \\
\hline 9978 & Landolt Collection & Europe & Switzerland & L. minor & L. × japonica* \\
\hline 9979 & Landolt Collection & Europe & Germany & L. minor & L. minor \\
\hline 9980 & Landolt Collection & Europe & Germany & L. minor & L. $\times$ japonica* \\
\hline 9982 & Landolt Collection & North America & USA & L. japonica & L. ×japonica \\
\hline 9983 & Landolt Collection & Europe & Switzerland & L. japonica & L. ×japonica \\
\hline 9986 & Landolt Collection & North America & USA & L. minor & L. × japonica* \\
\hline 9991 & Landolt Collection & North America & USA & L. japonica & L. × japonica \\
\hline $8784 b$ & Landolt Collection & Europe & Sweden & L. japonica & L. $\times$ japonica \\
\hline $9425 a$ & Landolt Collection & Europe & Italy & L. gibba & L. gibba $\times$ L. Minor * \\
\hline BOG0024 & Greifswald University & Europe & Germany & L. turionifera & L. turionifera \\
\hline BOG0071 & Greifswald University & Europe & Germany & L. turionifera & L. turionifera \\
\hline BOG0072 & Greifswald University & Europe & Germany & L. turionifera & L. turionifera \\
\hline KJA007 & Jena University & Europe, Asia & Russia & L. turionifera & L. turionifera \\
\hline
\end{tabular}




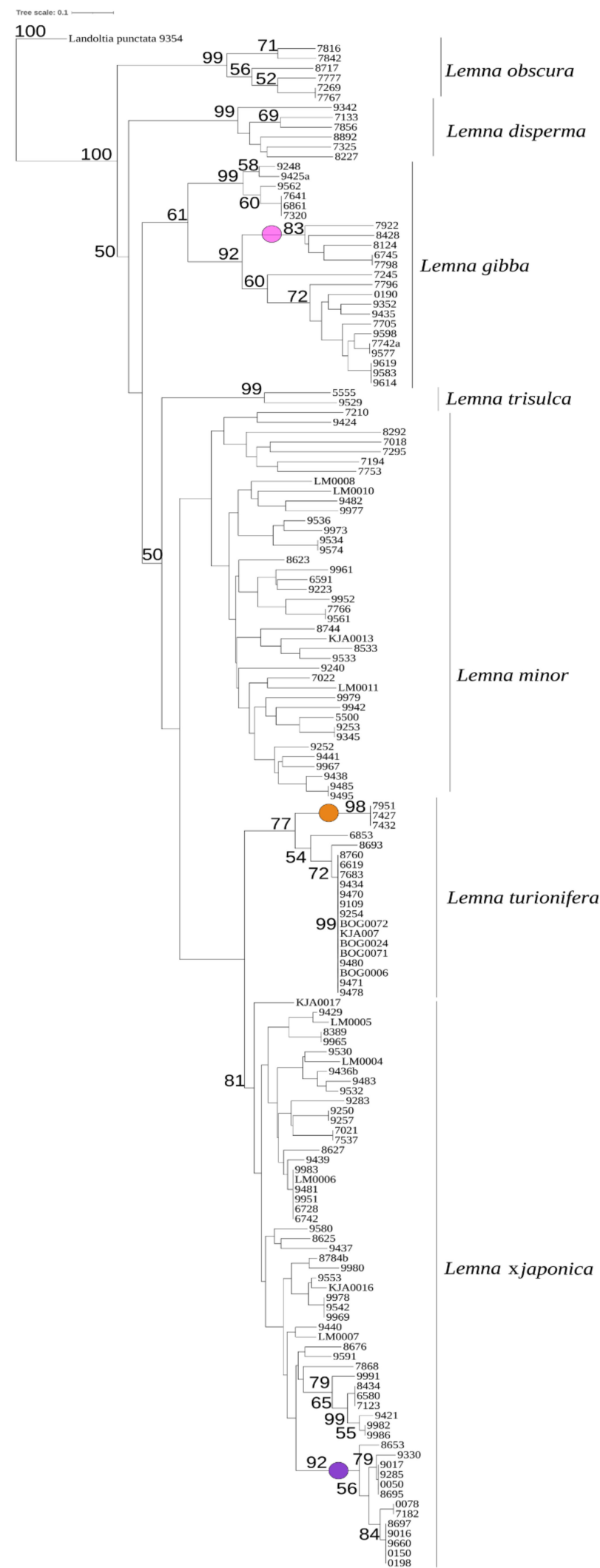

Figure 1. Neighbor joining similarity tree of 156 duckweed clones belonging to Lemna sect. Lemna, inferred through TBP fragment analysis (1st and 2nd intron regions). Landoltia punctata 9354 was used as outgroup to root the tree. The estimated bootstrap values (1000 replicates, $>50 \%$ ) are reported at the branch node. Colored dots highlight sub-cluster grouping clones with shared geographic origin: pink, L. gibba from America; orange, L. turionifera from East Asia; violet, L. $\times$ japonica from East Asia). 
The TBP data were also used to infer a principal component analysis (PCA) to further describe the genetic diversity among clones belonging to the four most represented species, L. minor, L. ×japonica, L. gibba and L. turionifera (Figure 2). The cumulative contribution of the first three principal components explains $63 \%$ of the total variation, providing a clear description of the relationships among species, concurrently revealing hybrid entries, which grouped separately. This was the case of $L$. $\times$ japonica clones, including those originally classified as L. minor, which were clearly separated from the putative parental species L. minor and L. turionifera, along the plot axes.

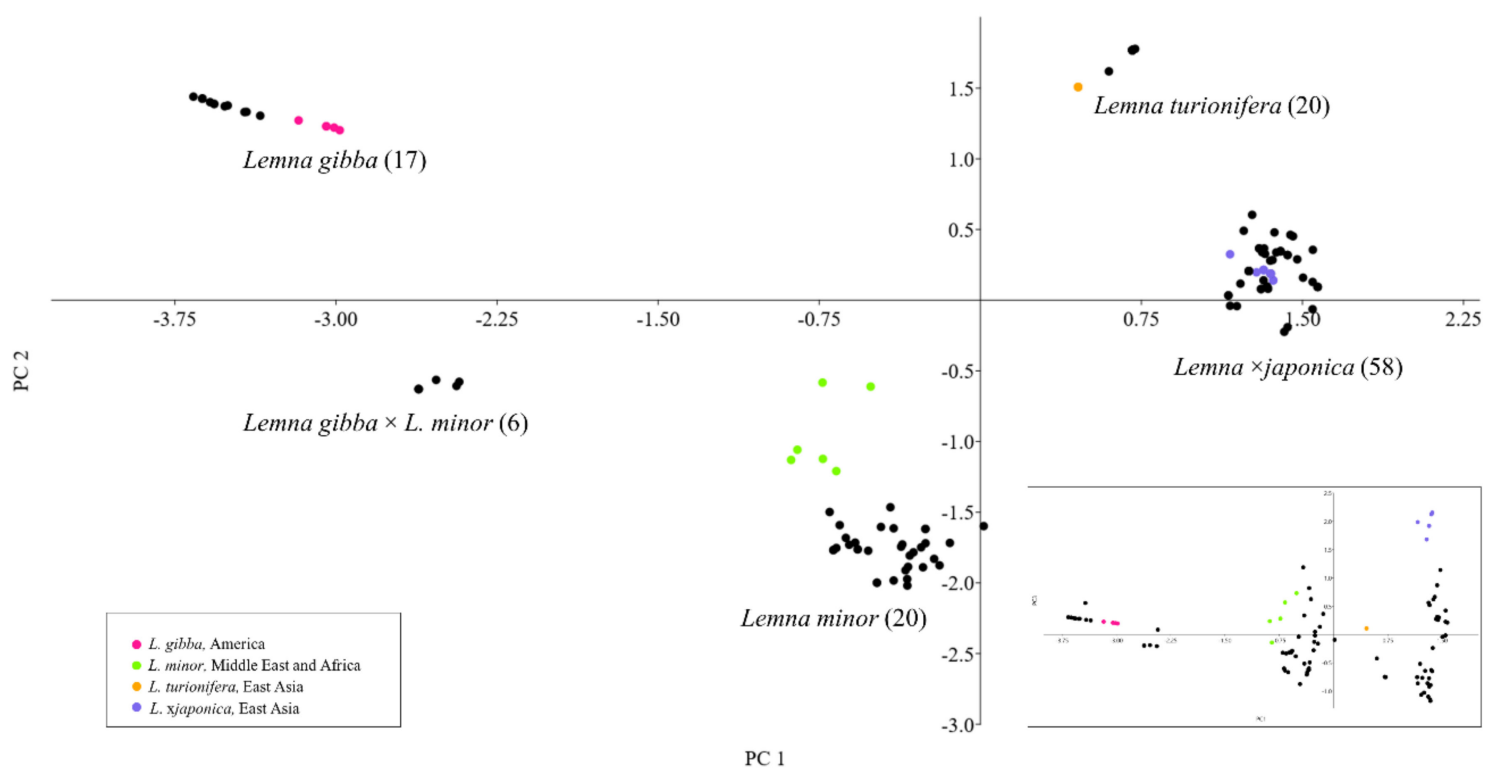

Figure 2. Principal components analysis (PCA) plot based on genetic distances between clones of L. minor, L. $\times$ japonica, L. gibba and L. turionifera, inferred from TBP analysis (PC1 and PC2). In the insert, the plot of PC1 and PC3 shows the distribution of $L$. $\times$ japonica clones. Clone IDs are omitted and the total number of analyzed clones per species is reported in brackets. Colored dots highlight only clones of each species forming the subclusters with shared geographic origin shown in Figure 1. The color code of dots is in accordance.

Similarly, an additional group, with respect to the four recognized species, was formed by six clones, mentioned above as the Mediterranean group, classified as L. gibba by morphology and representing one of two sister clades of the L. gibba cluster observed in the dendrogram of Figure 1. The bi-dimensional plot placed this group of clones in an intermediate position between L. minor and L. gibba, suggesting shared alleles with both species. This prompted us to further investigate if the aforementioned group of six clones could be considered a separate taxon, possibly a hybrid. In the plot and thereafter we then refer to this group as Lemna gibba $\times$ Lemna minor (see below).

In addition, within each species, isolated subgroups can be recognized as spread apart from the main clusters by the first three components of the PCA (Figure 2). In accordance with the dendrogram in Figure 1, the subgrouping distribution shown by the PCA is congruent with the geographical origin of clones (colored dots in Figure 2). Notably, in L. minor a group of clones from the Middle East and Africa was significantly spread apart from the respective main group.

\subsection{Reclassification of Clones by TBP}

The correspondence between the original morphological characterization of the analyzed clones and TBP results is summarized in Table 2, which reports misidentifications for each species and the kind of error involved. L. obscura, L. trisulca and L. disperma were the most easily identified species with a $100 \%$ correct assignment, although a reduced number of clones was available, and results are not included in the Table. The overall 
misidentification rate by morphology was $28.6 \%$ considering five species (treating L. gibba $\times$ L. minor hybrid as a separate taxon). Classification by morphology failed to correctly identify $48 \%$ of $L$. $\times$ japonica clones, considering them as L. minor (30\%), L. gibba $(14 \%)$, and L. turionifera (5\%). Fifty-five percent of supposed ' $L$. gibba' turned out to be either L. $\times$ japonica $(25 \%)$ or the newly described hybrid L. minor $\times$ L. gibba $(30 \%)$. In just two cases each, clones of L. turionifera and L. gibba were exchanged for $L$. $\times$ japonica. It is therefore clear that most incorrect identifications involved hybrids, which were often classified as one of the parental species. The new classification of all clones according to TBP is given in Table 1.

Table 2. Misidentification rate: correlation between morphological classification and TBP analysis.

\begin{tabular}{|c|c|c|c|c|c|c|c|c|}
\hline \multicolumn{9}{|c|}{ ТВP } \\
\hline & Species & L. minor & L. turionifera & L. $\times$ japonica & L. gibba & $\begin{array}{c}\text { L. gibba } \times \\
\text { L. minor }\end{array}$ & Tot. $\mathbf{n}$ & $\%$ Incorrect \\
\hline \multirow{7}{*}{ 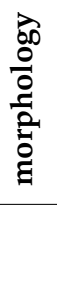 } & L. minor & 21 & & 11 & & & 32 & 34.3 \\
\hline & L. turionifera & & 16 & 2 & & & 18 & 11.1 \\
\hline & L. $\times$ japonica & & 1 & 19 & 1 & & 21 & 9.5 \\
\hline & L. gibba & & & 5 & 9 & 6 & 20 & 55.0 \\
\hline & L. gibba $\times$ L. minor & & & & & 0 & 0 & 0.0 \\
\hline & tot. $\mathrm{n}$ & 21 & 17 & 37 & 10 & 6 & 91 & 28.6 \\
\hline & $\%$ incorrect & 0.0 & 5.9 & 48.6 & 10.0 & 100.0 & 28.6 & \\
\hline
\end{tabular}

The high rate of misidentification of $L . \times$ japonica has at least two direct implications:

- $\quad$ The abundance of $L$. × japonica populations was highly underestimated, as well as its geographical distribution, which is not limited to Japan, Korea and the east coast of China, as reported by Landolt for L. japonica [16]. The actual distribution, deduced from investigated clones and shown in Figure 3, covers all the temperate regions from Eastern Asia to Central Asia, Europe and North America, although their invasive origin in the different regions remains to be elucidated. One clone was even found in South Africa (Figure 3).

- At least part of the huge variability observed in L. minor, e.g., in genome size, ploidy or physiological parameters etc. could be due to erroneous classification of clones.
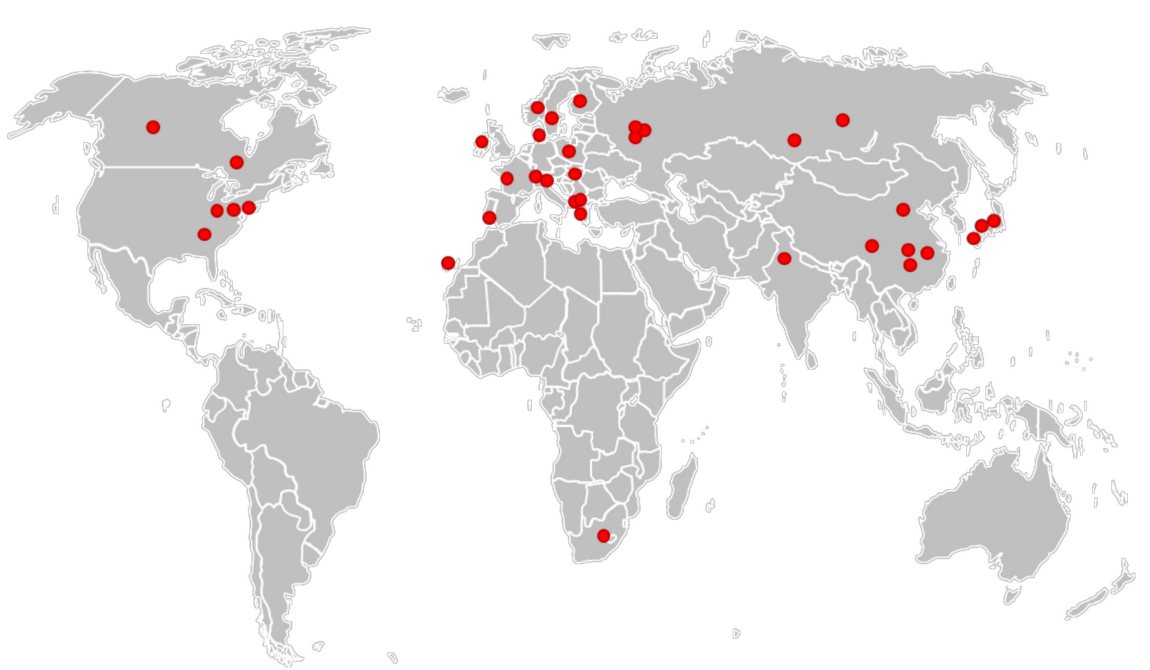

Figure 3. Geographical distribution of the analyzed clones of L. × japonica.

\subsection{Lemna gibba $\times$ Lemna Minor Hybrids}

Comparison of electrophoretic TBP profiles of the six clones in the L. gibba subcluster with those of other species revealed additional peaks attributable to L. minor, definitively 
confirming the hypothesis of interspecific hybridization between the two species. As shown in Figure 4, the additivity of the peak profiles in the hybrid clones witness the presence of two subgenomes. However, karyotyping will be needed in order to determine if hybrids are allotetraploids, as usually expected for interspecific hybrids, or homoploids, as it can be the case for asexually reproducing plants. Each TBP amplicon was assigned to the correspondent $\beta$-tubulin locus, based on the sequences retrieved from Whole-genome sequencing (WGS) data of L. minor 5500 [31] (https:/ / genomevolution.org/r/ik6h (accessed on 14 November 2021), ID 27408), L. minor 8627, here reclassified as L. ×japonica, and L. gibba 7742a (https:/ / www.lemna.org/ (accessed on 14 November 2021)). The two sets of six parologous TUBB loci in L. minor and L. gibba were arbitrarily numbered TUBB1-TUBB6, in the absence of rules for tubulin gene numbering in plants. Corresponding positions on chromosomes or contigs of WGS data are given in Supplementary Table S2. An additional $\beta$-tubulin sequence, likely a pseudogene, was retrieved only from the L. gibba WGS data. In fact, its sequence lacks the canonical two introns and has a short deletion in the second exon, leading to its interpretation as a retrotransposed copy of TUBB2 by sequence similarity, and therefore named $\Psi T U B B 2$. This sequence is nevertheless amplified by TBP primers, producing a short fragment of 250 base pairs distinctive of L. gibba (Figure 4).

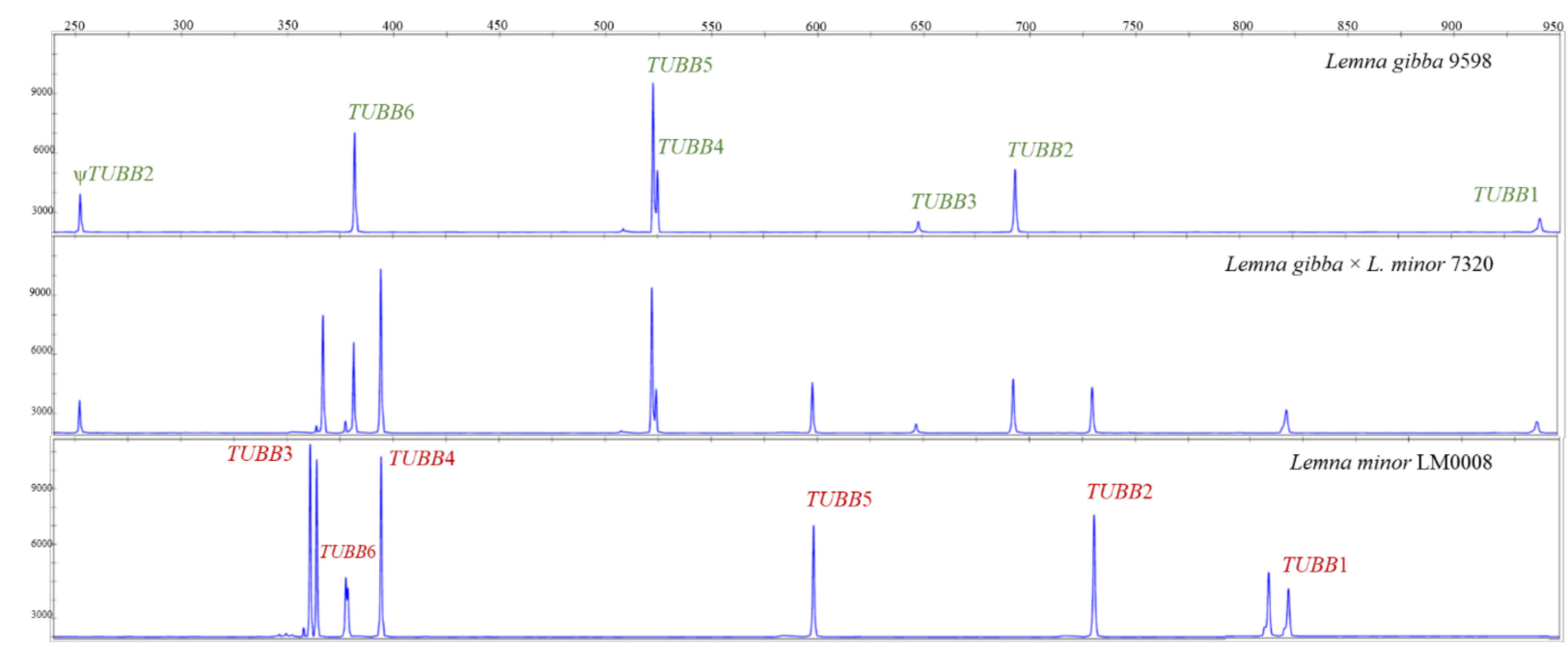

Figure 4. TBP profiles of representative clones of $L$. gibba $\times$ L. minor hybrids and the two putative parental species $L$. minor and L. gibba. Peak size is expressed in base pairs and peak height in Relative Fluorescence units. TUBB loci corresponding to each peak, as deduced from expected amplicon size, are indicated. Doublets indicate length variant heterozygosity at TUBB3 and TUBB1 loci in LM0008.

The possibility of an artefact originating from the analysis of cross-contaminated clones was excluded by sub-cloning twelve single fronds of each clone and performing the TBP analysis on each clonal population after one week's cultivation. Profiles were identical to those of the original clones (not shown). On this base, we therefore concluded that we have identified a new interspecific hybrid in the genus, between L. minor and L. gibba, to add to L. × japonica.

Plastid intergenic spacers $p s b \mathrm{~K}-p s b \mathrm{I}$ and $a t p \mathrm{~F}-a t p \mathrm{H}$ were used to identify the maternal parent of each putative hybrid clone. Interestingly, both reciprocal crosses were observed: clones 9425 a and 9248 have maternal inheritance of $L$. gibba, whereas plastid markers of clones 7641, 7320, 6861, 9562 matched the L. minor sequences (Supplementary Table S3). This seems different from what was found in L. Xjaponica, where all clones so far investigated by plastid barcoding sequencing have L. minor as the maternal parent. Interestingly, the two reciprocal crosses were separated by cluster analysis. 


\subsection{Frond Morphology and Flowering}

All six L. gibba $\times$ L. minor clones showed a flat morphology of the frond under standard culture conditions. Frond shape was quite heterogeneous among clones, from almost round to ovate, generally asymmetrical. An overview is given in Figure 5 . They were also different in size, with the two L. minor $\times$ L. gibba (9425a and 9248) showing larger fronds than the reverse crosses (Average length 4.45 vs. $3.88 \mathrm{~mm}$, average width 3.01 vs. $2.62 \mathrm{~mm}$ ). We will present elsewhere a more detailed, formal description of the new hybrid species L. gibba $\times$ L. minor.

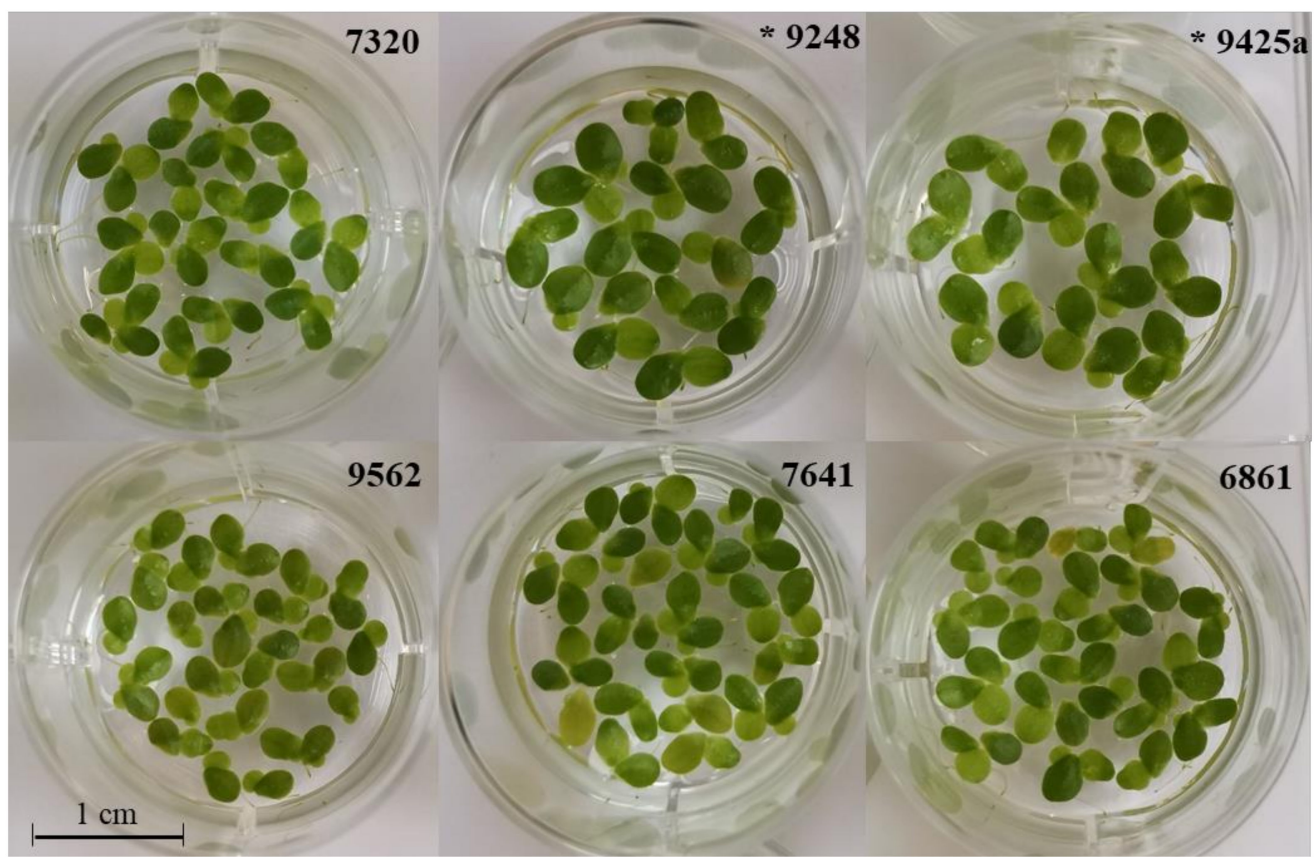

Figure 5. Cultures of each of the six hybrid clones L. gibba $\times$ L. minor: 9562, 7641, 6861, 7320, 9425a and 9248. Asterisks $\left(^{*}\right)$ indicate clones with $L$. gibba as the female maternal parental.

Descriptions of supposed intermediate forms between L. gibba and L. minor are reported in the literature. In particular, a new species from Southern Italy was described in 1973 as a possible hybrid between the two species and was named L. symmeter Giuga, species nova [12] is now considered as a synonym of L. gibba [32]. The name comes from the most distinctive trait reported for the new species, which is the symmetric (simultaneous) development of stamens during flower development. This is different from what described by Kandeler [7] and by Giuga himself about flowering in L. gibba, characterized by the appearance of the first anther together or soon after the stigma, later followed by the second anther. The new species was described as sterile, as fruit formation and seed setting was never observed.

We tried to verify if the hybrid clones that we have identified could correspond to putative 'L. symmeter' on these criteria, by inducing flowering through treatment with salicylic acid (SA) as reported by others [33,34]. After four weeks of cultivation in $20 \mu \mathrm{M}$ SA, we were able to induce flowering in two out of three L. gibba clones (7742a and 9598, not 8124), but neither the six hybrid clones, nor two L. minor clones (9977 and 9942) showed reproductive organs after six weeks. Therefore, we have not yet been able to provide proof of the identity of the hybrid clones with the previously described species L. symmeter.

\subsection{Infrasectional Structure of Lemna Sect. Lemna}

The infrageneric structure of the genus Lemna is not unequivocally defined because of conflicting results obtained by the nuclear ribosomal coding and noncoding sequences, and plastid markers [21] and/or possible misclassification of some clones used for these 
studies. Nevertheless, a phylogenetic tree was obtained by merging a large number of sequence data $[4,21]$. The finding of hybrids calls for an update to that tree. Fast evolving intron regions are suitable for phylogenetic analysis of closely related taxa [35], particularly if a low recombination rate is expected, as in the case of predominant clonal propagation in duckweeds. We chose two $\beta$-tubulin introns showing little or no intraspecific length variability by TBP profiling and designed gene-specific primers for cross-species amplification, at their exon-intron borders. After optimization of primers and PCR conditions, the first intron of TUBB2 and the second intron of TUBB1 were amplified in all species of the section with the same two primer pairs. PCR amplification is shown in Figure 6, which also highlights the hybrid origin of $L$. $\times$ japonica and $L$. gibba $\times$ L. minor by the presence of markers of the same length of those shown by the two parental sub-genomes. Intron size was quite conserved among the different species, with the exception of the second TUBB1 intron of L. gibba and L. obscura, showing large deletions. No amplification was obtained on clones of other Lemna sections with the same primers (not shown).

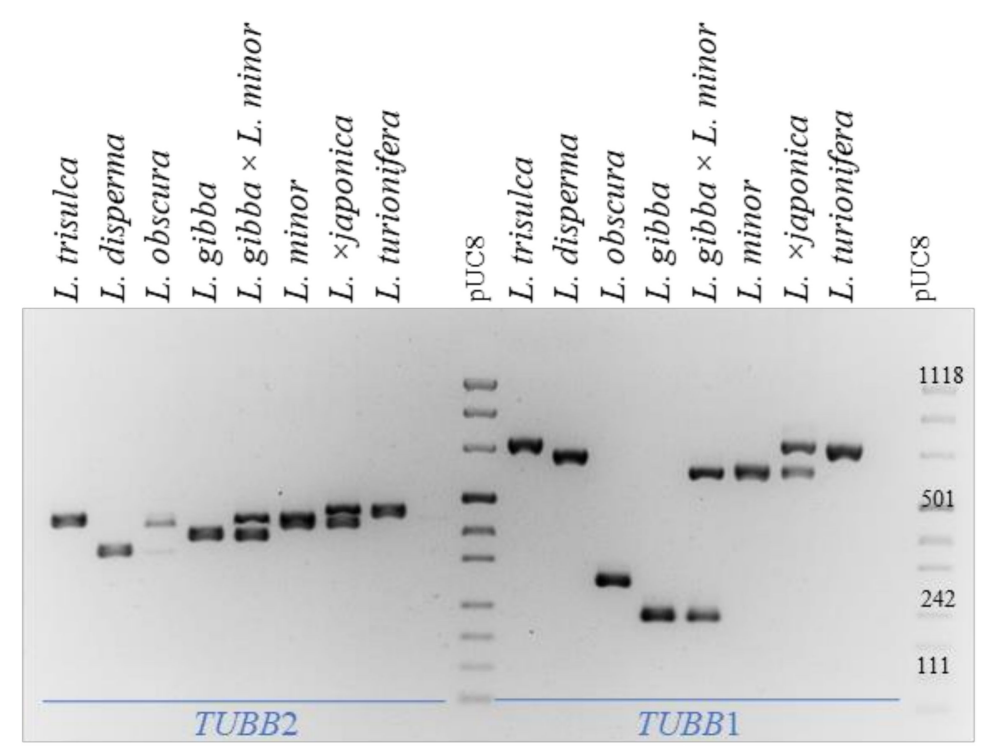

Figure 6. Cross-species PCR amplification of TUBB2 and TUBB1 in each species and hybrids of Lemna sect. Lemna.

Gene trees were obtained by concatenation of the two regions (sequences are provided in Supplementary Table S4). Intron sequences of both hybrid species, almost identical (>99\% identity) to both parental species, were not included in the alignment. The TUBB2 sequence of Spirodela polyrhiza, was used to root the tree. Equivalent tree topologies were obtained by both Maximum Parsimony and Maximum Likelihood clustering methods (not shown). The gene tree is congruent with that proposed by Tippery 2015 [21] showing Lemna sect. Lemna as split in two subclusters, one comprising L. gibba, L. disperma and L. minor and the second L. turionifera, L. trisulca and L. obscura. In that tree, $L$. $\times$ japonica was the closest relative of L. minor, for the obvious influence of the L. minor plastid sequences. A phylogenetic reconstruction of the section based on the TUBB gene tree and showing the origin of the two interspecific hybrids is shown in Figure 7. 


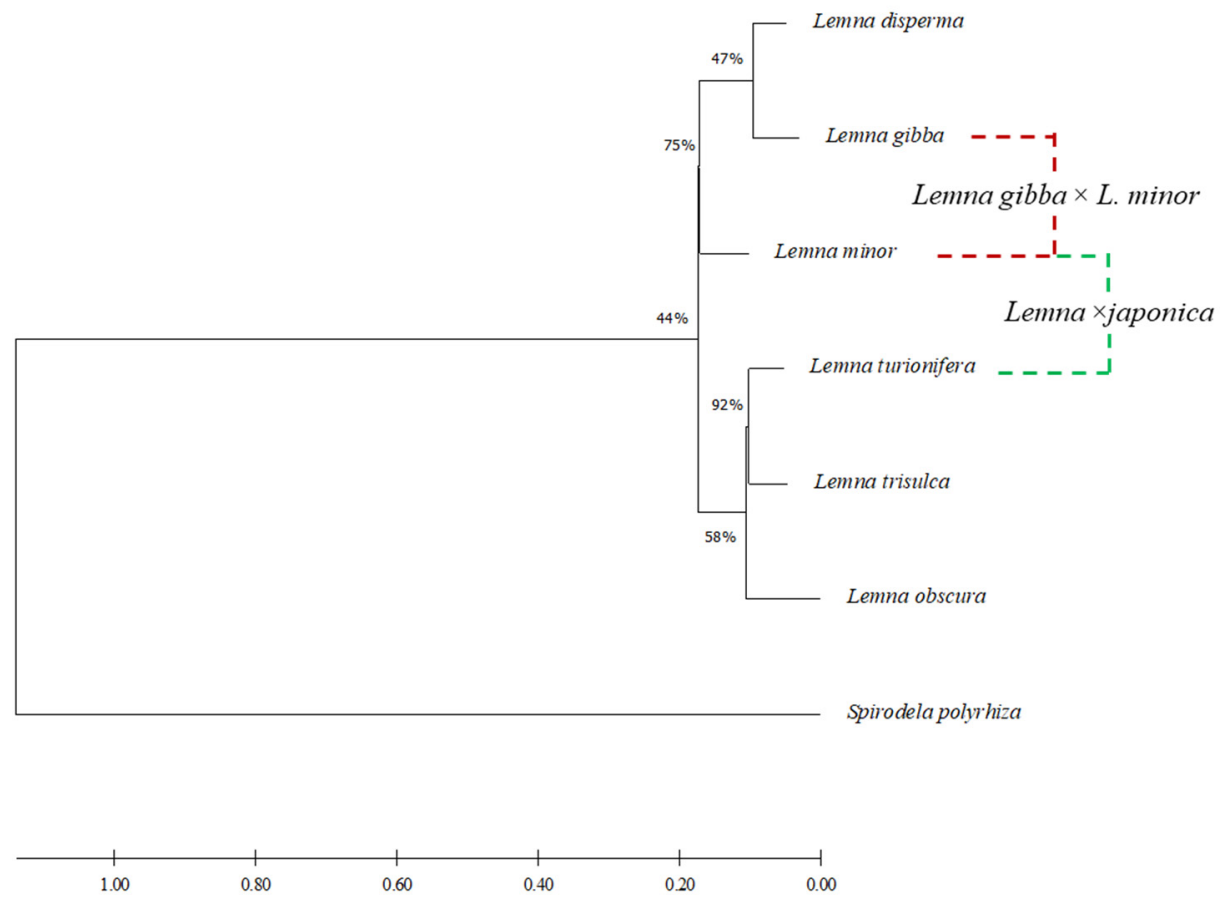

Figure 7. Maximum likelihood tree inferred from the alignment of concatenated loci TUBB2 and TUBB1 for all species of Lemna sect. Lemna. Bootstrap values are shown on the specific branches. Interspecific hybrids were manually inserted on the tree; relative branches are not to scale.

\subsection{Intraspecific TUBB2 Polymorphism in Lemna gibba and Lemna minor}

As clones from different geographical origin clustered separately by TBP, we searched for intraspecific polymorphisms in TUBB2 first intron sequences by investigating 18 clones of L. minor and 13 clones of $L$. gibba (Supplementary Table S4). PCR amplicons were directly sequenced. All L. minor and most L. gibba (supposedly diploids), were homozygous at the TUBB2 locus, generating unique sequence profiles. Sequences of six L. gibba clones could not be obtained due to the superimposition of two separate sequence chromatograms within the same frame, likely arising from length variant heterozygosis. We did not further investigate these clones. Fourteen polymorphic sites out of 410 positions investigated in TUBB2 were identified among L. minor clones, producing four different sequence variants, here referred to as haplotypes (M1-M4). In L. gibba, eight polymorphic sites were found over 380 base pairs, defining three haplotypes, named G1-G3 (Table 3).

Table 3. TUBB2 polymorphic sites and corresponding haplotypes.

\begin{tabular}{|c|c|c|c|c|c|c|c|c|c|c|c|c|c|c|c|c|}
\hline & \multirow[t]{2}{*}{ Haplotype } & \multicolumn{14}{|c|}{ Polymorphic Sites } & \multirow{2}{*}{$\frac{\text { Alignment Length (bp) }}{407}$} \\
\hline \multirow{5}{*}{ 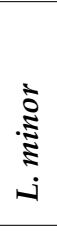 } & & 35 & 45 & 86 & 175 & 177 & 184 & 197 & 206 & 249 & 286 & 316 & 330 & 337 & 366 & \\
\hline & M1 & $\mathrm{T}$ & A & $\mathrm{T}$ & G & $\mathrm{C}$ & $\mathrm{C}$ & $\mathrm{T}$ & $\mathrm{T}$ & A & $\mathrm{C}$ & G & G & G & A & \\
\hline & M2 & $\mathrm{C}$ & G & G & $\mathrm{T}$ & G & $\mathrm{T}$ & A & G & $\mathrm{T}$ & $\mathrm{T}$ & A & $\mathrm{A}$ & $\mathrm{A}$ & $\mathrm{T}$ & \\
\hline & M3 & $\mathrm{T}$ & A & $\mathrm{T}$ & $\mathrm{T}$ & $\mathrm{C}$ & $\mathrm{C}$ & $\mathrm{T}$ & $\mathrm{T}$ & A & $\mathrm{C}$ & G & $\mathrm{G}$ & G & A & \\
\hline & M4 & $\mathrm{T}$ & A & $\mathrm{T}$ & $\mathrm{T}$ & $\mathrm{C}$ & $\mathrm{C}$ & $\mathrm{T}$ & $\mathrm{T}$ & A & $\mathrm{C}$ & A & G & G & A & \\
\hline & & 40 & 68 & 109 & 224 & 250 & 255 & 302 & 329 & & & & & & & 380 \\
\hline 5 & G1 & $\mathrm{T}$ & $\mathrm{T}$ & C & G & $\mathrm{C}$ & $\mathrm{T}$ & A & G & & & & & & & \\
\hline है & G2 & - & $\mathrm{T}$ & C & $\mathrm{G}$ & $\mathrm{T}$ & $\mathrm{T}$ & A & $\mathrm{G}$ & & & & & & & \\
\hline j & G3 & - & A & $\mathrm{T}$ & - & $\mathrm{T}$ & $\mathrm{C}$ & $\mathrm{C}$ & $\mathrm{T}$ & & & & & & & \\
\hline
\end{tabular}


The TUBB2 sequences of clones L. minor 5500 and L. gibba 7742a, retrieved from WGS data, were used as references (M1 and G1) for the calculation of the number of polymorphisms. Association of the different haplotypes to each clone is reported in Table 4. In L. minor, the separation of an African genetic pool was evident from the sharing of twelve conserved SNPs defining haplotype M2 among the three investigated clones, evident, whereas the Euro-Asiatic clones showed by far larger sequence identity, with 1-2 SNPs.

Table 4. Association of the TUBB haplotypes to the analyzed clones.

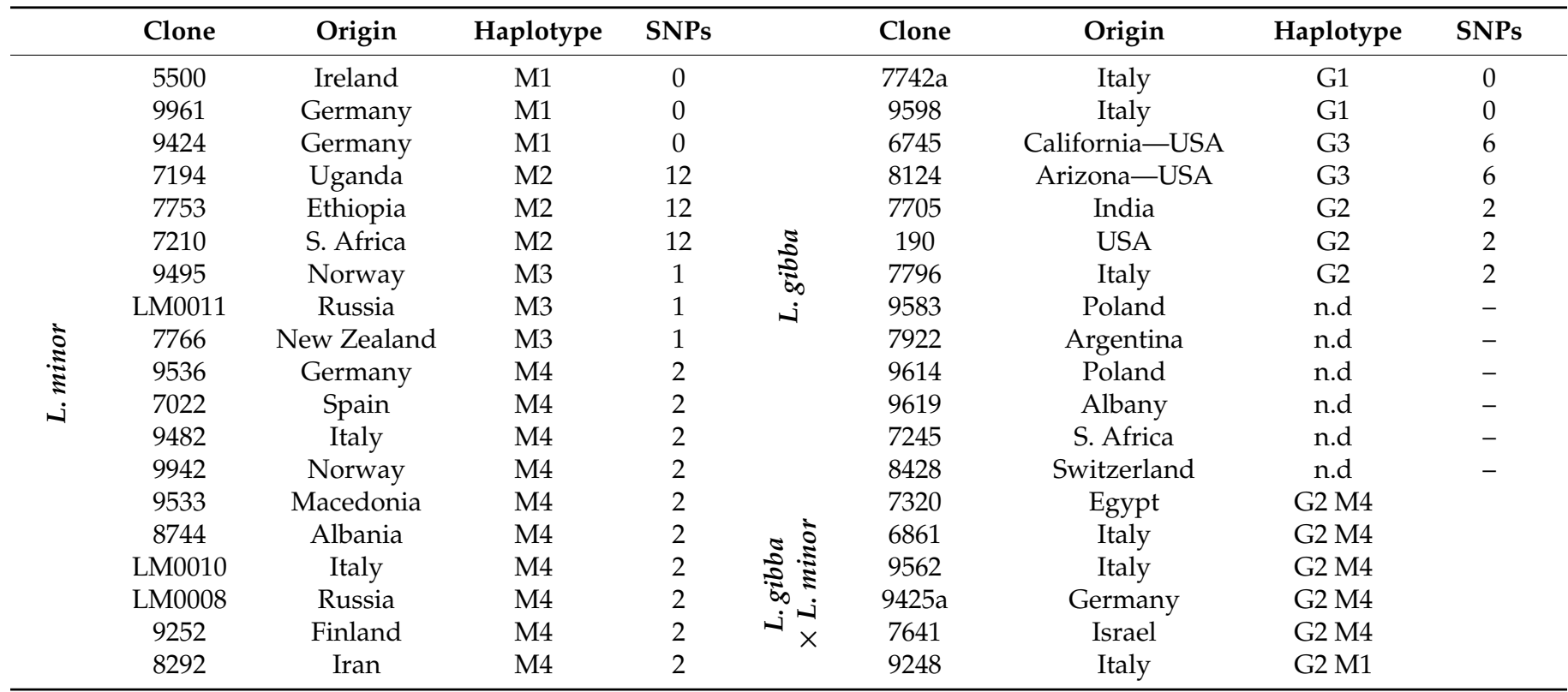

The number of substitutions is reported with respect to L. minor 5500 and L. gibba 7742a taken as references. n.d, sequence with overlapping peaks in the chromatogram.

In L. gibba, two clones from the American lineage, genetically distinct from others clones (Figures 1 and 2), showed the same holotype G3, characterized by the presence of six SNPs (Single Nucleotide Polymorphism).

We also looked for parental genome signatures in the six clones L. gibba $\times$ L. minor by sequence analysis of the TUBB2 homoeologous loci, after amplification with selective primers for the two subgenomes $\mathrm{G}$ and $\mathrm{M}$. Interestingly, five out of six clones showed the same haplotype at both loci suggesting their common origin and excluding contributions from the American L. gibba and African L. minor genomic pools. The sixth clone differs for its $\mathrm{M}$ haplotype. The high degree of sequence identity between hybrids and the parental species suggests a quite recent origin, with respect to the differentiation of Lemna species.

\section{Discussion}

Species delimitation by morphology can be highly challenging in duckweeds. Within the genus Lemna sect. Lemna is the most problematic, as it includes closely related species which show blurred boundaries due to high intraspecific and low interspecific variability of morphological traits, as L. japonica, L. minor and L. gibba. Even plastid barcoding markers, easily discriminating $L$. minor from $L$. gibba, fails to separate $L$. japonica from $L$. minor. In this work, we extended a previous molecular survey by TBP to 98 additional duckweed clones, mostly from the Landolt Duckweed Collection, classified by morphology as belonging to species of sect. Lemna. The analysis provided further support to the identification of L. $\times$ japonica as a hybrid and led to the identification of a new interspecific hybrid within this section. This is clearly shown in the PCA plot obtained from the TBP dataset, with clear separation of two clusters of hybrid clones sharing L. minor as the donor of one subgenome and having L. turionifera and L. gibba, respectively, as the other parental species. 


\subsection{Lemna $\times$ japonica}

Natural interspecific hybrids between L. minor and L. turionifera were identified in our previous work [20] by TBP cluster analysis as a subcluster merging accessions classified as L. japonica and L. minor by morphology and nested within the L. turionifera branch. This larger analysis, including many more L. turionifera, L. minor and L. japonica clones, further supported previous evidence that all clones in this cluster are definitely genetically separated from true L. minor, despite their similar morphology. All of them have a duplicate set of six $\beta$-tubulin genes and highly similar TBP profiles (Supplementary Table S1). Therefore, we suggest referring the whole taxonomic unit to $L$. $\times$ japonica, to account for its hybrid ancestry. Moreover, TBP profiling is a suitable method to distinguish $L$. $\times$ japonica from L. minor on a molecular base, in addition to morphology. Accordingly, thirty-six percent of 'L. minor' clones was identified as $L$. $\times$ japonica by TBP analysis. Misidentifications of $L$. $\times$ japonica with $L$. minor clones could not be easily recognized before, as plastid markers are not able to resolve the two species [27] and GBS, while detecting some genetic distance between the two species, is not manageable for single clone identification [5].

Although more powerful genetic approaches, including sequencing and karyotype analysis, must be used to address this point, a certain degree of genetic variability within L. $\times$ japonica is already evident from TBP analysis, separating East Asian and American subclusters (Figure 1) distinct in some private alleles. The species L. japonica originally described by Landolt 1980 [18] as the L. minor biotype originally present in Japan and Eastern China could possibly coincide with the East-Asian subcluster. Accordingly, all L. $\times$ japonica clones from China and Japan were correctly classified by morphology, suggesting that either they have more canonical traits or that the geographical origin was a determinant for classification. As a further consequence of misclassification, $L$. $\times$ japonica has a broader geographical distribution than previously reported for L. japonica by Landolt, as it is present in all temperate regions of Eurasia and North America.

Misidentification of some $L$. × japonica clones as L. minor could also partially explain the large variability in genome size (ranging from 356 to $604 \mathrm{Mb}$ ) and the variable chromosome numbers, $40-50$, attributed to $L$. minor $[14,15,36]$. For example, at least four $L$. minor clones having higher DNA content according to Wang [14] (550-600 Mb; clone 9016, 9436b, 9439 and 9440) are classified as L. × japonica by TBP (the present work), in line with the genome size of the L. japonica holotype clone 7182, assessed as $600 \mathrm{Mb}$ [14]. Conversely, other clones also identified as $L$. $\times$ japonica by TBP $(7210,7123$ and 8434$)$ showed a lower DNA content, around $400 \mathrm{Mbp}$. However, these clones have different geographical origin, coming either from the American (7123 and 8434) or the African continent (7210).

One possible explanation of these results is that hybridization between L. minor and L. turionifera has occurred more than once, thus originating independent lineages of L. $\times$ japonica with different ploidy or chromosome rearrangements as reported for other plant genera, e.g., Senecio spp. [37,38], or Tragopogon spp. [39].

However, large differences in genome size can also be produced by different proliferation of Transposable Elements (TEs) in different lineages with the same ploidy level. This is widely documented for sunflower (Helianthus annuus) where three different homoploid hybrid species, independently originated from the same two parents, featured genome sizes larger then parental species (approximately 5.3-5.6 Gb with respect to 3.3 and 3.5 $\mathrm{Gb}$ ), mainly represented by TEs [40]. Further work is ongoing in order to understand if $L$. $\times$ japonica is monophyletic or may have originated from multiple hybridization events.

\subsection{Lemna gibba $\times$ Lemna minor}

The second interspecific cluster that was separated by the PCA plot consisted of six clones, all recorded as $L$. gibba by morphology, with overlapping TBP profiles between L. minor and L. gibba. While waiting for a formal description including morphological traits (manuscript in preparation), we will refer to it as L. gibba $\times L$. minor even knowing that the six hybrid clones have originated from both reciprocal crosses of the two parental species. 
The finding of this new hybrid was not completely unexpected as intermediate phenotypes between $L$. minor and $L$. gibba were already described in the past [7-9,11]. The difficulty in distinguishing these two species, when not flowering, has been widely reported in the literature, particularly when individuals of L. gibba do not show the typical gibbosity. In facts, 'flat forms' of L. gibba often occur under culture conditions or seasonally, at some sites in the wild. Confusion may also arise between L. gibba and L. ×japonica, as shown in our survey.

We believe that the L. gibba $\times$ L. minor hybrid could correspond to a Lemna species described as 'L. symmeter' [12]. The description of this new species was reported in a monographic publication, written in Italian with only the abstract in English, entitled "Vita segreta di Lemnacee" (The secret life of Lemnaceae) [12]. According to the description, the new Lemna species was first observed by the author in 1968, along the coast of Campania (Southern Italy) and later at different sites in Southern Italy where, over the many years, was always found in mixed populations with L. gibba (30-90\%), rarely associated with L. minor or L. trisulca. In these mixed populations, L. gibba could easily be distinguished by the pronounced gibbosity, typical of most Italian genotypes. Since then, the existence of 'L. symmeter' has never been confirmed and the original clones went missing. Since the description was not supported by a formal diagnosis in Latin, the putative new species is not valid and 'L. symmeter' is currently reported as a synonym of L. gibba. According to Giuga's description, flower development becomes the most distinctive trait in the absence of gibbosity. Flowering of 'L. symmeter' was reported to differ from that of L. gibba for the simultaneous growth of the two anthers, occurring a few days after the stigma. Moreover, anthers were reported as indehiscent and seed setting, frequent in L. gibba, has never been observed.

Unfortunately, we have so far been unable to induce flowering in any of the hybrid clones to confirm the most important diagnostic trait described by Giuga. However, the present work has demonstrated, by molecular markers and by nuclear sequence analysis that a hybrid species compatible with the description of 'L. symmeter' indeed exists, and is unlikely to be rare in the wild as six clones are present in the Landolt collection. All clones but one came from the Mediterranean basin, three of them (9248, 9562 and 6861) from different Italian regions, from North to South, supporting their correspondence with putative ' $L$. symmeter'. This is also supported by a recent survey in Central Italy, in which 13 Lemna spp. samples, out of 56 collected at different stations, could not be unequivocally identified by morphology and were described as 'non-gibbous form of L. gibba or L. minor'. Plastid marker sequencing assigned all of them to L. minor [41]. One clone from that study (9562), originally sent by the authors to Prof. K.J. Appenroth at the University of Jena was then delivered to the Landolt Duckweed Collection, is one of the six clones recognized as hybrid in our work. It is therefore likely that such hybrids are often identified as 'flat forms' of L. gibba and are widely distributed in Italy. Hybrid discovery in Egypt (clone 7320) and Israel (7641) suggests they are adapted to the Mediterranean climate, while the clone collected in Hamburg Germany, (9425a), could be explained either as a recent invasion or the result of local hybridization occurred in that area. Mixed populations of $L$. gibba and L. minor have been repeatedly reported by De Lange in The Netherlands [9]. Despite their high morphological similarity to the parental species, L. gibba $\times$ L. minor must have some physiological and ecological features that confer increased fitness in competition with L. gibba in certain conditions. Therefore, physiological and ecological properties should be investigated, as well as the true geographical distribution of the hybrid must be recorded. To this end, we believe that TBP and/or the simpler PCR amplification with the genespecific primer pairs described in this work provide a simple tool for fast identification of the hybrid.

In conclusion, hybridization could have been one of the driving mechanism of duckweed evolution as it has been observed in other plant families, amounting to an average of $25 \%$ of plant species that are known to hybridize naturally with at least one other species [42]. What was more unexpected is that such hybridization occurs in plants which 
are reported to reproduce clonally and rarely flower in nature. However, extensive interlineage hybridization has been recently reported also for the predominantly clonal, aquatic plant Hydrilla verticillata [43].

\subsection{Lemna sect. Lemna}

Phylogenetic relationships in duckweeds have been established initially by combinations of morphological, flavonoid, allozyme and plastid DNA sequences [4] and subsequently a larger dataset including 73 accessions, have been produced using both plastid and nuclear ribosomal [21]. Despite some node resolved incongruently using the two kind of molecular markers, a solid consensus tree was obtained by the combination of both. Major conflicts in the genus Lemna were actually found in the section Lemna.

The existence of hybrid species, particularly L. × japonica, might explain conflicting results obtained with the use of plastid and nuclear loci and shed new light on the phylogenetic history of the genus. In this work, the phylogenetic tree of sect. Lemna was inferred from the alignment of two concatenated $\beta$-tubulin intron sequences, which deployed high interspecific variability, and further completed with the positioning of the two interspecific hybrid species. The tree topology was congruent with what reported by Tippery, 2015 [21], that place L. minor, L. turionifera and L. trisulca in a separate branch with respect to L. gibba, $L$ disperma and L. obscura. Interbreeding between species from the two branches of the tree demonstrates absent or incomplete reproductive isolation mechanisms between species of sect. Lemna. If extended to other duckweed species, this suggests that other hybrids could have originated where different species occur, or have occurred in the past, in sympatry, possibly explaining incomplete species separation by molecular markers also in species of other allied genera like Wolffia [27].

\subsection{Infraspecific Variation}

Despite large phenotypic and physiological infraspecific variability observed in duckweeds [44], genetic diversity is barely detectable by plastid markers, while nuclear ribosomal sequences, such as ETS and ITS, are not easily amplified in all species [21]. Although genome-wide approaches such as genotyping by sequencing or whole genome comparison are now economically affordable, such techniques require managing of huge datasets. Our study revealed that infraspecific variation within $\beta$-tubulin intron sequences identifies haplotypes associated with a particular continent. This suggests that these sequences can detect greater genetic diversity than could be estimated using plastid markers. Further investigations based on $\beta$-tubulin introns may help revealing biogeographical patterns due to intraspecific variation in other species, e.g., L. ×japonica.

Conversely, TUBB intron sequences obtained for some hybrid clones revealed very high similarity to those of the parent species, suggesting either recent hybridization, or very low mutation rates, as it was shown for species in the allied genus Spirodela Schleiden [45].

Accurate identification and understanding of the genetic structure are important elements for application purposes or when managing populations of invasive species such as the native American species L. minuta Kunth, in Europe. Tubulin genes, combining highly conserved gene structure and exon sequences with highly variable intron regions, provided an effective toolkit for studying genetic relationships at both specific and subspecific level in duckweeds, providing new directions for further investigations by whole genome approaches.

\section{Materials and Methods}

\subsection{Plant Material and Cultivation}

Plant material, including 98 duckweed clones, mostly from the Landolt Duckweed Collection, and named with the four-digit code as defined by Landolt, is summarized in Table 1. Information about additional clones included in the cluster analyses of the present paper can be found in [20]. Lemna clones were aseptically cultivated in $90 \mathrm{~mm}$ Petri dishes on agarized Schenk and Hildebrandt (SH) medium (plant agar 8 g/L, Duchefa 
Biochemia, Haarlem, NL) with $2 \mathrm{~g} / \mathrm{L}$ sucrose, at pH 5.1 [46]. Fronds were maintained at $25{ }^{\circ} \mathrm{C}$ under a 16-h photoperiod with light flux of $41-45 \mu \mathrm{mol} \mathrm{m}{ }^{-2} \mathrm{~s}^{-1}$ provided by white florescent lights.

\subsection{DNA Extraction and TBP Profiling}

We provide here a brief description of the protocol; the whole procedure is described in details in [20].

One hundred milligrams of fresh duckweed fronds were disrupted in $2 \mathrm{ml}$ tubes with three 3-mm stainless steel beads, using a TissueLyser II apparatus at a frequency of $30 \mathrm{~Hz}$ for $1 \mathrm{~min}$. The standard protocol of the DNeasy Plant Mini Kit (Qiagen, Valencia, CA, USA) was adopted for the extraction of total DNA, then the quality and amount were determined by UV absorbance with the Nanodrop 2000 C (Thermo Fisher Scientific, Inc., Waltham, MA, USA), and DNA was stored at $-20^{\circ} \mathrm{C}$ until used.

Thirty nanograms of gDNA was used as template for the TBP profiling (1st and 2nd intron). PCR primers, amplification protocols, as well all subsequent steps including Capillary Electrophoresis (CE) and the data collection were performed as reported [20]. Amplicon lengths (expressed in base pairs) of the CE-TBP profiles were used to analyze clones and the sorting of the numerical data were performed according to them. Both TBP 1st and 2nd intron markers (peaks size) were scored in a binary matrix $(1 / 0$, presence and absence respectively). The genetic similarity among genotypes was estimated according to the Jaccard's index for binary data, using the open source software package Past v.4.07b [47]. The multivariate analysis including the cluster distribution and the principal component analysis (PCA) were also performed through the same software. The dendrogram was computed by the neighbor joining (NJ) algorithm, and bootstrap confidence values were obtained applying 1000 replications. Minor graphical editing was performed using the online tool Interactive Tree Of Life (iTOL) v.6.4 [48].

\subsection{DNA Barcoding Analysis}

The plastid markers $a t p \mathrm{~F}-a t p \mathrm{H}$ and $p s b \mathrm{~K}-p s b \mathrm{I}$ were amplified with a modified version of the primers according to [27]. PCR reactions were run in a total volume of $20 \mu \mathrm{L}$, with 1 Unit of Platinum Taq DNA Polymerase and $0.5 \mu \mathrm{M}$ of each primer, using $20 \mathrm{ng}$ of template gDNA. Reactions were carried out by incubation at $95^{\circ} \mathrm{C}$ for $3 \mathrm{~min}$ followed by 30 cycles of $95^{\circ} \mathrm{C}$ for $40 \mathrm{~s}, 52{ }^{\circ} \mathrm{C}$ for $50 \mathrm{~s}, 72{ }^{\circ} \mathrm{C}$ for $1 \mathrm{~min}$ and a final extension of $72{ }^{\circ} \mathrm{C}$ for $3 \mathrm{~min}$. PCR products were checked on $2.0 \%$ agarose, $0.5 \times$ Tris Borate EDTA gels containing $1 \times$ Atlas ClearSight DNA Stain (Bioatlas, Tartu, EE, Estonia). PCR products were purified using the microCLEAN PCR/DNA Cleanup reagent, according to the manufacturer's instructions (Labgene Scientific SA, Châtel-Saint-Denis, $\mathrm{CH}$, Switzerland). The amplified products were forward and reverse sequenced (Microsynth, Balgach, Switzerland) and the obtained consensus sequence (contig) were considered for the alignment. The NCBI BLASTn analysis was performed for clone identification by best match analysis (http: / /www.ncbi.nlm.nih.gov (accessed on 14 November 2021)).

\section{4. $\beta$-. Tubulin Intron Amplification and Sequencing}

Gene-specific, cross-species primer pairs were designed on the sequence alignment of the chosen $\beta$-tubulin genes (TUBB1 and TUBB2) of L. minor clones 5500 and 8623 with the corresponding orthologs of $L$. gibba 7742, and tested for the simultaneous amplification of all the seven species belonging to Lemna sect. Lemna. More conserved regions encompassing intron borders were chosen for the primer design and degenerated nucleotides were introduced at polymorphic sites. TUBB2 cross-species primers (forward: I-FwTUBB2 5' CCT CCA GGG TAT GCG ATC-3' and reverse: I-Rv_11-23_1 $5^{\prime}$ - GGA ATC CTG CAM KTA AAT GAY G-3) targeted the first intron, whereas TUBB1 primers (forward: II-FwTUBB1 5'-CAC YCC AAG CTG TAA GWT CC-3' and reverse: II-Rv-TUBB15'- GAT CGC CGA CTA YAA GAA ATC-3') amplified the second intron. 
Furthermore, species-specific primers for the selective amplification of the L. gibba (forward I-FwTUBB2 $5^{\prime}$-CCT CCA GGG TAT GCG ATC-3' and reverse I-RvTUBB2g $5^{\prime}$-AAC TTG GAA TCC TGC AAG CA-3') and L. minor (forward 1_Fw_11-23_15'-TTC AGG GTA TGC GAT CTA TTC-3' and reverse 1_Rv_11-23_1 5'- GGA ATC CTG CAM KTA AAT GAY G-3') TUBB2 orthologous genes in interspecific hybrids were designed to target more specific regions of the same sequence alignment.

PCR was performed according to [20] after optimization of the annealing temperature; amplification products were purified using microCLEAN PCR/DNA Cleanup and directly sequenced on both strands. In the case of TUBB1 amplification on L. gibba $\times$ L. minor clones, the two amplified bands were cut from gel and purified with the MinElute Reaction Cleanup (Qiagen, Valencia, CA, USA). Forward and reverse sequences were inspected, manually edited where necessary, and combined in single consensus sequences.

\subsection{Bioinformatic Sequence Analysis}

Sequences were subjected to multiple sequence alignment using MUSCLE [49] implemented in MEGA X v.10.1.8 [50]. Alignments were manually edited and the evolutionary analysis was inferred by using the Maximum Likelihood method and General Time Reversible models [51]. Initial tree(s) for the heuristic search were obtained by applying the Neighbor-Joining method to a matrix of pairwise distances estimated using the Maximum Composite Likelihood (MCL) approach. The percentage of trees in which the associated taxa clustered together were estimated by bootstrap test (1000 replicates) and shown next to the tree branches. A discrete Gamma distribution was used to model evolutionary rate differences among sites $(+\mathrm{G}, 2$ categories) and the rate variation model $(+\mathrm{I})$ allowed for some sites to be evolutionarily invariable. The tree with the highest log likelihood was drawn to scale, with branch lengths measured in the number of substitutions per site.

\subsection{Flower Induction}

Fifty fronds for each of the 11 selected clones of L. minor (9977, 9942), L. gibba (9598, 8124) and L. gibba $\times$ L. minor $(9425 a, 6861,7641,9562,9248,7320)$ were aseptically cultured in Sterivent Low Containers $107 \mathrm{~mm} \times 94 \mathrm{~mm} \times 65 \mathrm{~mm}$ (Duchefa Biochemia, Haarlem, The Netherlands), in liquid SH medium supplemented with $2 \mathrm{~g} / \mathrm{L}$ sucrose and $20 \mu \mathrm{M}$ salicylic acid (SA). The trial was performed in the laboratory from mid-July to August for 40 days. Plastic boxes were positioned indoor in front of the window, under natural daylight (approx. $15 \mathrm{~h}$ day length) and avoiding direct sunlight, at room temperature $\left(23-28^{\circ} \mathrm{C}\right)$. Three replicates were set up for each clone, with an additional sample without SA as negative control. Flowers were observed from the 4th week.

Supplementary Materials: The following are available online at https:/ /www.mdpi.com/article/10 $.3390 /$ plants10122767/s1. Table S1: Alignment of the numerical output derived from the scoring of TBP fragment by capillary electrophoresis separation. Table S2: TUBB gene locations on chromosomes or contigs as from WGS data. Table S3: Plastid marker sequences from the analyzed clones. Table S4: TUBB sequences from the analyzed clones.

Author Contributions: Conceptualization, L.B. and L.M.; methodology, F.G. and S.G.; formal analysis, L.B. and J.D.G.; investigation, F.G., S.G. and J.D.G.; resources, D.B.; writing-original draft preparation, L.B.; writing - review and editing, L.M. and D.B.; visualization, F.G.; supervision, D.B.; funding acquisition, D.B. All authors have read and agreed to the published version of the manuscript.

Funding: This research received no specific funding.

Acknowledgments: We wish to thank W. Lämmler for providing most of the clones to be analyzed and useful information. We also thank KJ Appenroth and M. Bog for providing some additional clones. We are indebted to David Mabberley for valuable suggestions about the taxonomic treatment of the hybrid species and other useful comments.

Conflicts of Interest: The authors declare no conflict of interest. 


\section{References}

1. Martinov, I. Techno-Botanical Dictionary (Техно-ботаническийСловарь); Pechashano v Imperatorskoŭ Tipografii: Saint Petersburg, Russia, 1820.

2. Tippery, N.P.; Les, D.H. Tiny Plants with Enormous Potential: Phylogeny and Evolution of Duckweeds. In The Duckweed Genomes; Cao, X.H., Fourounjian, P., Wang, W., Eds.; Springer: Berlin, Germany, 2020; pp. 19-38. [CrossRef]

3. Bog, M.; Appenroth, K.; Sree, K. Key to the determination of taxa of Lemnaceae: An update. Nord. J. Bot. 2020, 38 , e02658. [CrossRef]

4. Les, D.; Crawford, D.; Landolt, E.; Gabel, J.; Kemball, R. Phylogeny and systematics of Lemnaceae, the duckweed family. Syst. Bot. 2002, 27, 221-240.

5. Bog, M. Genotyping-By-Sequencing for species delimitation in Lemna section Uninerves Hegelm (Lemnaceae). In The Duckweed Genomes; Cao, X.H., Fourounjian, P., Wang, W., Eds.; Springer: Berlin/Heidelberg, Germany, 2020; pp. 115-123. [CrossRef]

6. De Lange, L. Gibbosity in the complex Lemna gibba/Lemna minor: Literature survey and ecological aspects. Aquat. Bot. 1975, 1, 1327-1332. [CrossRef]

7. Kandeler, R. Species delimitation in the genus Lemna. Aquat. Bot. 1975, 1, 365-376. [CrossRef]

8. Landolt, E. Morphological differentiation and geographical distribution of the Lemna gibba-Lemna minor group. Aquat. Bot. 1975, 1, 345-363. [CrossRef]

9. de Lange, L.; Pieterse, A.H.; van Baarsen-Beckers, I. The occurrence of mixed populations of different genotypes of the Lemna gibba-Lemna minor complex. Acta Bot. Neerl. 1981, 30, 191-197. [CrossRef]

10. De Lange, L.; Pieterse, A.H. A comparative study of the morphology of Lemna gibba L. and Lemna minor L. Acta Bot. Neerl. 1973, 22, 510-517. [CrossRef]

11. Giardelli, M.L. Una nueva especia de Lemnacea de la Flora Argentina. Notas Del Mus. De La Plata 1937, 2, 97-100.

12. Giuga, G. Vita segreta di Lemnacee. In Lemna Symmeter G. Giuga-Species Nova; Blasio: Napoli, Italy, $1973 ;$ p. 19.

13. Bog, M.; Appenroth, K.; Sree, K. Duckweed (Lemnaceae): Its Molecular Taxonomy. Front. Sustain. Food Syst. 2019, 3, 117. [CrossRef]

14. Wang, W.Q.; Kerstetter, R.; Michael, T. Evolution of genome size in duckweeds (Lemnaceae). J. Bot. 2011, 2011, 570319. [CrossRef]

15. Hoang, P.; Schubert, V.; Meister, A.; Fuchs, J.; Schubert, I. Variation in genome size, cell and nucleus volume, chromosome number and rDNA loci among duckweeds. Sci. Rep. 2019, 9, 3234. [CrossRef] [PubMed]

16. Landolt, E. The family of Lemnaceae-A Monographic Study, Volume 1, Biosystematic investigations in the family of duckweeds (Lemnaceae). Ver. Geobot: Inst. ETH Shift. Rübel 1986, 71, 1-563.

17. Landolt, E. Contribution on the Lemnaceae of Ecuador. Fragm. Flor. Geobot. 2000, 45, 221-237.

18. Landolt, E. Description of six new species of Lemnaceae. E-Period. 1980, 70, 13-21.

19. Hirahaya, M.; Kadono, Y. Biosystematic study of Lemna minor L. sensu lato (Lemnaceae) in Japan with special reference to allozyme variation. Acta Phytotaxon. Geobot. 1995, 46, 117-129.

20. Braglia, L.; Lauria, M.; Appenroth, K.; Bog, M.; Breviario, D.; Grasso, A.; Gavazzi, F.; Morello, L. Duckweed Species Genotyping and Interspecific Hybrid Discovery by Tubulin-Based Polymorphism Fingerprinting. Front. Plant Sci. 2021, 12. [CrossRef] [PubMed]

21. Tippery, N.P.; Les, D.H.; Crawford, D.J. Evaluation of phylogenetic relationships in Lemnaceae using nuclear ribosomal data. Plant Biol. 2015, 17, 50-58. [CrossRef]

22. Ceschin, S.; Abati, S.; Leacche, I.; Zuccarello, V. Ecological comparison between duckweeds in central Italy: The invasive Lemna minuta vs the native L. minor. Plant Biosyst. 2018, 152, 674-683. [CrossRef]

23. Ceschin, S.; Leacche, I.; Pascucci, S.; Abati, S. Morphological study of Lemna minuta Kunth, an alien species often mistaken for the native L. minor L. (Araceae). Aquat. Bot. 2016, 131, 51-56. [CrossRef]

24. Bog, M.; Baumbach, H.; Schween, U.; Hellwig, F.; Landolt, E.; Appenroth, K. Genetic structure of the genus Lemna L. (Lemnaceae) as revealed by amplified fragment length polymorphism. Planta 2010, 232, 609-619. [CrossRef]

25. Bog, M.; Landrock, M.; Drefahl, D.; Sree, K.; Appenroth, K. Fingerprinting by amplified fragment length polymorphism (AFLP) and barcoding by three plastidic markers in the genus Wolffiella Hegelm. Plant Syst. Evol. 2018, 304, 373-386. [CrossRef]

26. Wang, W.; Wu, Y.; Yan, Y.; Ermakova, M.; Kerstetter, R.; Messing, J. DNA barcoding of the Lemnaceae, a family of aquatic monocots. BMC Plant Biol. 2010, 10, 205. [CrossRef] [PubMed]

27. Borisjuk, N.; Chu, P.; Gutierrez, R.; Zhang, H.; Acosta, K.; Friesen, N.; Sree, K.; Garcia, C.; Appenroth, K.; Lam, E. Assessment, validation and deployment strategy of a two-barcode protocol for facile genotyping of duckweed species. Plant Biol. 2015, 17, 42-49. [CrossRef] [PubMed]

28. Bardini, M.; Lee, D.; Donini, P.; Mariani, A.; Gianì, S.; Toschi, M.; Lowe, C.; Breviario, D. Tubulin-based polymorphism (TBP): A new tool, based on functionally relevant sequences, to assess genetic diversity in plant species. Genome 2004, 47, 281-291. [CrossRef] [PubMed]

29. Braglia, L.; Gavazzi, F.; Morello, L.; Gianì, S.; Nick, P.; Breviario, D. On the applicability of the Tubulin-Based Polymorphism (TBP) genotyping method: A comprehensive guide illustrated through the application on different genetic resources in the legume family. Plant Methods 2020, 16, 86. [CrossRef] [PubMed]

30. Gavazzi, F.; Braglia, L.; Mastromauro, F.; Giani, S.; Morello, L.; Breviario, D. The Tubulin-Based-Polymorphism Method Provides a Simple and Effective Alternative to the Genomic Profiling of Grape. PLoS ONE 2016, 11, e0163335. [CrossRef] [PubMed] 
31. Van Hoeck, A.; Horemans, N.; Monsieurs, P.; Cao, H.; Vandenhove, H.; Blust, R. The first draft genome of the aquatic model plant Lemna minor opens the route for future stress physiology research and biotechnological applications. Biotechnol. Biofuels 2015, 8, 188. [CrossRef]

32. Sree, K.; Bog, M.; Appenroth, K. Taxonomy of duckweeds (Lemnaceae), potential new crop plants. Emir. J. Food Agric. 2016, 28, 291-302. [CrossRef]

33. Fu, L.; Huang, M.; Han, B.; Sun, X.; Sree, K.; Appenroth, K.; Zhang, J. Flower induction, microscope-aided cross-pollination, and seed production in the duckweed Lemna gibba with discovery of a male-sterile clone. Sci. Rep. 2017, 7, 3047. [CrossRef]

34. Fourounjian, P.; Slovin, J.; Messing, J. Flowering and Seed Production across the Lemnaceae. Int. J. Mol. Sci. 2021, $22,2733$. [CrossRef]

35. Creer, S. Choosing and using introns in molecular phylogenetics. Evol. Bioinform. Online 2007, 3, 99-108. [CrossRef]

36. Acosta, K.; Appenroth, K.J.; Borisjuk, L.; Edelman, M.; Heinig, U.; Jansen, M.A.K.; Oyama, T.; Pasaribu, B.; Schubert, I.; Sorrels, S.; et al. Return of the Lemnaceae: Duckweed as a model plant system in the genomics and postgenomics era. Plant Cell 2021, 33, 3207-3234. [CrossRef]

37. Abbott, R.; Albach, D.; Ansell, S.; Arntzen, J.; Baird, S.; Bierne, N.; Boughman, J.; Brelsford, A.; Buerkle, C.; Buggs, R.; et al. Hybridization and speciation. J. Evol. Biol. 2013, 26, 229-246. [CrossRef] [PubMed]

38. Lowe, A.; Abbott, R. Hybrid swarms: Catalysts for multiple evolutionary events in Senecio in the British Isles. Plant Ecol. Divers. 2015, 8, 449-463. [CrossRef]

39. Novak, S.; Soltis, D.; Soltis, P. Ownbey Tragopogons-40 Years Later. Am. J. Bot. 1991, 78, 1586-1600. [CrossRef]

40. Renaut, S.; Rowe, H.C.; Ungerer, M.C.; Rieseberg, L.H. Genomics of homoploid hybrid speciation: Diversity and transcriptional activity of long terminal repeat retrotransposons in hybrid sunflowers. Philos. Trans. R. Soc. B Biol. Sci. 2014, 369, 20130345. [CrossRef]

41. Marconi, G.; Landucci, F.; Rosellini, D.; Venanzoni, R.; Albertini, E. DNA barcoding as a tool for early warning and monitoring alien duckweeds (Lemna sp.pl.): The case of Central Italy. Plant Biosyst. 2019, 153, 660-668. [CrossRef]

42. Mallet, J. Hybrid speciation. Nature 2007, 446, 279-283. [CrossRef] [PubMed]

43. Benoit, L.K.; Les, D.H.; King, U.M.; Na, H.R.; Chen, L.; Tippery, N.P. Extensive interlineage hybridization in the predominantly clonal Hydrilla verticillata. Am. J. Bot. 2019, 106, 1622-1637. [CrossRef] [PubMed]

44. Sree, K.; Sudakaran, S.; Appenroth, K. How fast can angiosperms grow? Species and clonal diversity of growth rates in the genus Wolffia (Lemnaceae). Acta Physiol. Plant. 2015, 37, 204. [CrossRef]

45. Xu, S.; Stapley, J.; Gablenz, S.; Boyer, J.; Appenroth, K.; Sree, K.; Gershenzon, J.; Widmer, A.; Huber, M. Low genetic variation is associated with low mutation rate in the giant duckweed. Nat. Commun. 2019, 10, 1243. [CrossRef] [PubMed]

46. Schenk, R.; Hildebrandt, A. Medium and techniques for induction and growth of monocotyledonous and dicotyledonous Plant-Cell Cultures. Can. J. Bot. 1972, 50, 199-204. [CrossRef]

47. Hammer, Ø.; Harper, D.; Ryan, P. PAST: Paleontological statistics software package for education and data analysis. Palaeontol. Electron. 2001, 4, 9.

48. Letunic, I.; Bork, P. Interactive Tree Of Life (iTOL) v5: An online tool for phylogenetic tree display and annotation. Nucleic Acids Res. 2021, 49, W293-W296. [CrossRef] [PubMed]

49. Edgar, R. MUSCLE: Multiple sequence alignment with high accuracy and high throughput. Nucleic Acids Res. 2004, 32, 1792-1797. [CrossRef]

50. Kumar, S.; Stecher, G.; Li, M.; Knyaz, C.; Tamura, K. MEGA X: Molecular Evolutionary Genetics Analysis across Computing Platforms. Mol. Biol. Evol. 2018, 35, 1547-1549. [CrossRef]

51. Nei, M.; Kumar, S. Molecular Evolution and Phylogenetics; Oxford University Press: New York, NY, USA, 2000. 